\title{
INTERACTION OF RAILWAY WITH TURNOUT
}

\author{
Jerzy Kisilowski ${ }^{*}$, Elżbieta Kowalik-Adamczyk ${ }^{2}$
}

${ }^{1}$ Kazimierz Pulaski University of Technology and Humanities, Faculty of Transport, Electrical Engineering and Computer Science, Poland, email: j.kisilowski@uthrad.pl

${ }^{2}$ Kazimierz Pulaski University of Technology and Humanities, Faculty of Transport, Electrical Engineering and Computer Science, Poland, email:e.kowalik-adamczyk@uthrad.pl

*Corresponding autho

Reviewed positively: 05.09.2019

Information about quoting an article:

Kisilowski J., Kowalik-Adamczyk E. (2019). Interaction of railway with turnout. Journal of civil engineering and transport. 1(1), 39-47. DOI: 10.24136/tren.2019.004

Abstract - The paper presents a mathematical model of the switch point with R radius $>1200 \mathrm{~m}$. The switch point was treated as a beam with variable stiffness and variable moment of inertia. A simulation was performed for a constant force loading the switch point and for real parameters of the switch point with $R=1200 \mathrm{~m}$.

Key words - turnout, railroad vehicle, eigenmodes, curvaturees

\section{INTRODUCTION}

In recent years, the problem of the dynamics of railway vehicle-turnout has been the subject of a number of publications. The basic ones are publications from [1] to [19] In these works, the problems of dynamics in the systems in which the track stiffness was assumed to be constant were considered. The phenomena occurring during the passage of a railway vehicle through a blade (movement on a turning track), in which the switch point would be a curved beam (curvature of a turnout e.g. radius $\mathrm{R}=1200 \mathrm{~m}$ ) with variable stiffness and variable moment of inertia, were not considered. Some fragments of these considerations can be found in works [20] and [21]. Moreover, in the paper [22] the dynamic phenomena of a rail vehicle passing through a crossing of an ordinary turnout were investigated. In this paper, the track stiffness in the area of the frog was taken into account, which is twice as high as in the normal track.
The paper presents the process of examining the dynamic phenomena of rail vehicle-turnout (switch point and frog) using the method of computer simulation.

\section{Mathematical Model of RaIlWAY Vehicle dynamics THROUGH A RAILWAY TURNOUT}

The turnout structure will be presented as a mechanical system and a mathematical model of moving force (rail vehicle) along a beam with variable stiffness and curvature of radius $R$.

The mechanical system of the turnout is shown in Figure 1.

Passing a railway vehicle on the switch point is a branchoff track movement. In motion through route the switch point does not take part.

It is important to examine the dynamic behavior of a rail vehicle turnout at a switch over to determine the alternating time load acting on the switch point and frog.

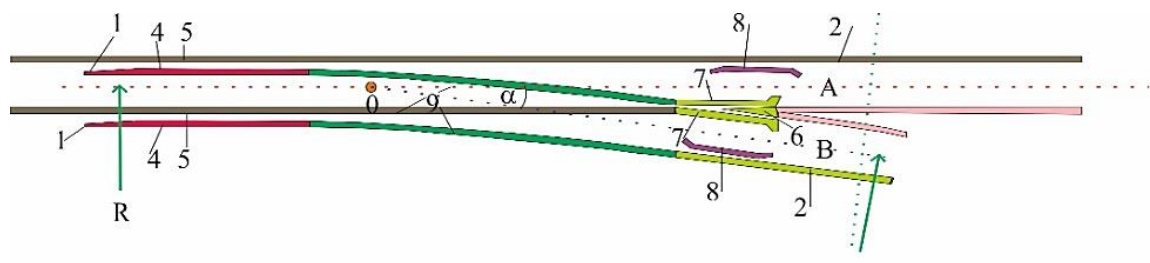

$\mathrm{R}$

Fig. 1. The basic components and geometrical elements of the regular turnout are: beginning of turnout 1 (in pre-switch point contact); end of turnout 2 (in contact after the crossing); turnout geometric center 0 , which is the intersection of the stock rail axis with the closure rail axis; radius $\mathrm{R}$ of the closure rail curve; turnout angle $\alpha$ (angle between the axes of the stock rail and the closure rail), slant of the turnout - tan $\alpha$ - expressed as a fractional fraction with one in the numerator; the last turnout of the 3rd turnout; switch points 4; rheostats 5; crossing 6; wing rails 7; guard rails 8 ; connecting rails 9; $A O B$ triangle 
In Kryloff's and Bleich's work [6] analytical considerations were performed for a beam with a constant cross-section, however, the foundation (usually assumed to be a constant size) on which the beam supported on subsequent sleepers was located was omitted (the spacing between the sleepers has a constant value of about $0.6 \mathrm{~m}$ ). This type of solution is based on variable separation methods, so that the solution determining the individual displacements of the beam is defined on a finite sum of spatial-time functions.

In the process of determining the mathematical description defining the variable load on the needle, in the first step the mechanical model of the load inducing system should be determined. In order to be able to use numerical methods in calculating the deformations of the switch point, treated as a beam with a variable cross-section. Only the vertical load Po was taken into consideration (Fig. 2).

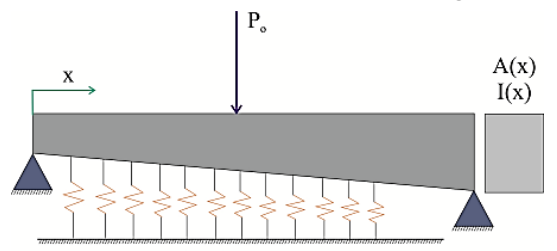

Winkler foundation

Fig. 2. Load force acting on the switch point

The mathematical formula for the balance of the switch point model is as follows:

$$
-\frac{\partial \mathrm{Q}(\mathrm{x}, \mathrm{t})}{\partial \mathrm{x}}-\mathrm{p}_{0} \cdot \delta(\mathrm{x}-v \mathrm{t})=\rho(\mathrm{x}) \cdot \frac{\partial^{2} \mathrm{w}}{\partial \mathrm{t}^{2}}
$$
by:

The forces present in the analyzed model were defined

$$
\partial \mathrm{M}(\mathrm{x}, \mathrm{t})=\mathrm{Q}(\mathrm{x}, \mathrm{t}) \partial \mathrm{x} \Rightarrow \frac{\partial \mathrm{M}(\mathrm{x}, \mathrm{t})}{\partial \mathrm{x}}=\mathrm{Q}(\mathrm{x}, \mathrm{t})
$$

where $\delta$ is a function of the Dirac delta to take account of the actual load distribution reflecting the wheel-switch point pressure in the force applied, velocities of $v$ are taken into account, while $\mathrm{x}$ determines the linear coordinates describing the variation of the load force in the interval $(x \in[0, L])$ and $\rho(x)$ determines the material density in the interval $[\mathrm{M} / \mathrm{L}]$.

Balance of moments occurring on the switch point under load:

$$
\begin{gathered}
-\frac{\partial\left(\frac{\partial \mathrm{M}(\mathrm{x}, \mathrm{t})}{\partial \mathrm{x}}\right)}{\partial \mathrm{x}}-\mathrm{p}_{0} \cdot \delta(\mathrm{x}-\mathrm{vt})=\rho(\mathrm{x}) \cdot \frac{\partial^{2} \mathrm{w}}{\partial \mathrm{t}^{2}} \\
\frac{\partial^{2} \mathrm{M}(\mathrm{x}, \mathrm{t})}{\partial \mathrm{x}^{2}}-\mathrm{p}_{0} \cdot \delta(\mathrm{x}-\mathrm{vt})=\rho(\mathrm{x}) \cdot \frac{\partial^{2} \mathrm{w}}{\partial \mathrm{t}^{2}}
\end{gathered}
$$

In the next step, inserting moments into the equation of forces was obtained:

$$
\frac{\frac{\partial^{2} w(x, t)}{\partial x^{2}}}{1+\left(\frac{\partial w}{\partial x}\right)^{2}} \approx \frac{\partial^{2} w(x, t)}{\partial x^{2}}=\frac{M(x, t)}{E I(x)}
$$

$$
\mathrm{M}(\mathrm{x}, \mathrm{t})=\mathrm{EI}(\mathrm{x}) \cdot \frac{\partial^{2} \mathrm{w}(\mathrm{x}, \mathrm{t})}{\partial \mathrm{x}^{2}}
$$

Taking into consideration the examined element in the process of determining the equations describing physical phenomena on a beam of variable cross-section, the EulerBernoulli beam equation was used for the analysis, in which a linear relation between the occurring moment and the switch point curvature was assumed. The equation describing the dynamics of the beam was inserted into the relation (4). As a result, second order differential equations were obtained, defining the deformation of a beam with a variable cross-section due to a variable load, equation is defined as:

$$
\begin{gathered}
\frac{\partial^{2} \mathrm{EI}(\mathrm{x}, \mathrm{t}) \cdot \frac{\partial^{2} w(x, t)}{\partial x^{2}}}{\partial \mathrm{x}^{2}}-\mathrm{p}_{0} \cdot \delta(\mathrm{x}-\mathrm{vt})=\rho(\mathrm{x}) \cdot \frac{\partial^{2} w}{\partial \mathrm{t}^{2}} \\
\rho(\mathrm{x}) \cdot \frac{\partial^{2} w}{\partial \mathrm{t}^{2}}+\frac{\partial^{2}}{\partial \mathrm{x}^{2}}\left[\mathrm{EI}(\mathrm{x}) \cdot \frac{\partial^{2} \mathrm{w}(\mathrm{x}, \mathrm{t})}{\partial \mathrm{x}^{2}}\right]+ \\
+\mathrm{p}_{0} \cdot \delta(\mathrm{x}-\mathrm{vt})=0
\end{gathered}
$$

To solve the partial differential equation, specify the initial conditions:

$$
\begin{gathered}
\mathrm{w}(\mathrm{s}, 0)=0, \forall \mathrm{x} \\
\left.\frac{\partial \mathrm{w}(\mathrm{x}, \mathrm{t})}{\partial \mathrm{t}}\right|_{\mathrm{t}=0}=0, \forall \mathrm{x}
\end{gathered}
$$

\section{DEFORMATIONS OCCURRING IN THE SWITCH POINT}

Taking into account the element of the switch point length $L$ and the load occurring on it, shown on the following Figure 3 determines the forces and moments at the nodes.

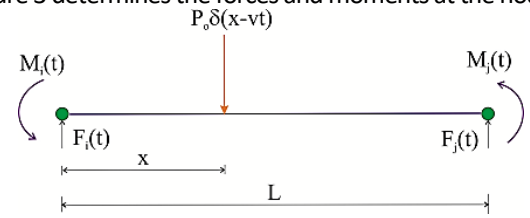

Fig. 3. Dynamics of the switch point with variable load

The forces on the beam with the moments are determined by:

$$
\begin{gathered}
F_{i}^{b}=Q(0, t) \\
F_{j}^{b}=-Q(L, t) \\
M_{i}^{b}=-M(0, t) \\
M_{j}^{b}=M(L, t)
\end{gathered}
$$

Normal force:

$$
P_{0} \cdot \delta(x-v t)
$$

The force of inertia is described as:

$$
\rho(x) \cdot \frac{\partial^{2} w(x, t)}{\partial t^{2}}
$$


Thus, in the initial $y$ axis coordinate at point 0 , assuming that $x \in[0, L]$ the relation to the bending moment is determined:

$$
\frac{\partial Q(x, t)}{\partial x}=-P_{0} \cdot \delta(x-v t)-\rho(x) \cdot \frac{\partial^{2} w(x, t)}{\partial t^{2}}
$$

As a result of mathematical transformations it was obtained

$$
\mathrm{Q}(\mathrm{x}, \mathrm{t})=\mathrm{Q}(0, \mathrm{t})-\int_{0}^{\mathrm{x}} \mathrm{P}_{0} \cdot \xi(\xi-v \mathrm{t}) \mathrm{d} \xi-\int_{0}^{\mathrm{x}} \rho(\xi) \frac{\partial^{2} \mathrm{w}(\xi, \mathrm{t})}{\partial \mathrm{t}^{2}} \mathrm{~d} \xi
$$

The bending moments at the start and end of the beam are determined by:

$$
\begin{gathered}
\frac{\partial M(x, t)}{\partial x}=Q(x, t) \cdot d x \\
M(x, t)=M(0, t)+\int_{0}^{x} Q(\xi, t) d \xi
\end{gathered}
$$

At this point, using the finite element method, we move on to the formulation of the Euler-Bernoulli partial differential equation of a curved beam with a variable cross-

section with a deflection function, $w(x)$. In order to obtain the main equation describing the dynamics of the switch point, the initial conditions were defined:

$$
\begin{aligned}
& \frac{\partial w(x, t)}{\partial x}=w^{\prime}(x, t) \\
& \frac{\partial w(x, t)}{\partial t}=\dot{w}(x, t)
\end{aligned}
$$

Then the initial conditions were inserted into the relation (8) and the result was obtained:

$$
\begin{gathered}
\rho(x) \cdot \ddot{w}(x, t)+\left(w^{\prime \prime}(x, t) \cdot E I(x)\right)^{\prime \prime}=-P_{0} \cdot \delta(x-v t) \\
\rho(x) \cdot \ddot{w}(x, t) \cdot u w^{*}(x)+\left(w^{\prime \prime}(x, t) \cdot E I(x)\right)^{\prime \prime} \cdot w^{*}(x)=-P_{0} \cdot \delta(x-v t) \cdot w^{*}(x)
\end{gathered}
$$

Later on, using mathematical transformations, it was obtained:

$$
\int_{0}^{L} \rho(x) \cdot \ddot{w}(x, t) \cdot u^{*}(x) d x+\int_{0}^{L}\left(w^{\prime \prime}(x, t) \cdot E l(x)\right)^{\prime \prime} \cdot w^{*}(x) d s=-\int_{0}^{L} P_{0} \cdot \delta(x-v t) \cdot w^{*}(x) d x
$$

Integrating the first part of the equation (25) phrase by parts has been obtained:

$$
\begin{aligned}
\int_{0}^{\mathrm{L}}\left(\mathrm{w}^{\prime \prime}(\mathrm{x}, \mathrm{t}) \cdot\right. & \operatorname{EI}(\mathrm{x}))^{\prime \prime} \cdot \mathrm{w}^{*}(\mathrm{x}) \mathrm{d} \mathrm{x} \\
& =\left.\mathrm{w}^{*}(\mathrm{x}) \cdot\left(\mathrm{w}^{\prime \prime}(\mathrm{x}, \mathrm{t}) \cdot \operatorname{EI}(\mathrm{x})\right)^{\prime}\right|_{0} ^{\mathrm{L}} \\
& \left.-\int_{0}^{\mathrm{L}} \mathrm{w}^{\prime \prime}(\mathrm{x}, \mathrm{t}) \cdot \operatorname{EI}(\mathrm{x})\right)^{\prime} \cdot \frac{\partial \mathrm{w}^{*}(\mathrm{x})}{\partial \mathrm{x}} \mathrm{ds}=\left.\mathrm{w}^{*}(\mathrm{x}) \cdot\left(\mathrm{w}^{\prime \prime}(\mathrm{x}, \mathrm{t}) \cdot \operatorname{EI}(\mathrm{x})\right)^{\prime}\right|_{0} ^{\mathrm{L}} \\
& -\left.\left(\mathrm{w}^{\prime \prime}(\mathrm{x}, \mathrm{t}) \cdot \mathrm{EI}(\mathrm{x})\right) \cdot \frac{\partial \mathrm{w}^{*}(\mathrm{x})}{\partial \mathrm{x}}\right|_{0} ^{\mathrm{L}}-\left.\left(\mathrm{w}^{\prime \prime}(\mathrm{x}, \mathrm{t}) \cdot \operatorname{EI}(\mathrm{x})\right) \cdot \frac{\partial \mathrm{w}^{*}(\mathrm{x})}{\partial \mathrm{x}}\right|_{0} ^{\mathrm{L}} \\
& +\int_{0}^{\mathrm{L}} \mathrm{w}^{\prime \prime}(\mathrm{x}, \mathrm{t}) \cdot \operatorname{EI}(\mathrm{x}) \cdot \frac{\partial \mathrm{w}^{*}(\mathrm{x})}{\partial \mathrm{x}} \mathrm{dx}
\end{aligned}
$$

Taking into account the deformations at the beginning and ends of the beam, the moments due to action the load force added to the top surface of a curved variable crosssection beam determined by:

$$
\mathrm{Q}(\mathrm{x}, \mathrm{t})=\left(\mathrm{w}^{\prime \prime} \cdot \mathrm{EI}(\mathrm{x})\right)^{\prime}
$$

Therefore equations (23) and (24) will take on a form:

$$
\begin{gathered}
\left.\left(w^{\prime \prime} \cdot \operatorname{EI}(x)\right)^{\prime} \cdot w^{*}(x)\right|_{0} ^{L}=\left.Q(L, t) \cdot w^{*}(x)\right|_{0} ^{L}=Q(L, t) \cdot w^{*}(L)-Q(0, t) \cdot w^{*}(0)=-F_{j}^{b} \cdot w^{*}(L)-F_{i}^{b} \cdot w^{*}(0) \\
\left.w^{\prime \prime} \cdot E I(s) \cdot \frac{\partial \cdot w^{*}(s)}{\partial s}\right|_{0} ^{L}=\left.M(s) \cdot \frac{\partial w^{*}}{\partial s}\right|_{0} ^{L}=-\left.M_{j}^{b} \cdot \frac{\partial w^{*}}{\partial s}\right|_{L}-\left.M_{i}^{b} \cdot \frac{\partial w^{*}}{\partial s}\right|_{0}
\end{gathered}
$$

In turn the second part of equation (26) will look like this: 


$$
\int_{0}^{\mathrm{L}}\left(\mathrm{w}^{\prime \prime}(\mathrm{s}, \mathrm{t}) \cdot \mathrm{El}(\mathrm{s})\right)^{\prime \prime} \cdot \mathrm{w}^{*}(\mathrm{~s}) \mathrm{dx}=\int_{0}^{\mathrm{L}} \mathrm{w}^{\prime \prime}(\mathrm{s}, \mathrm{t}) \cdot \mathrm{EI}(\mathrm{s}) \cdot \frac{\partial^{2} \mathrm{w}^{*}(\mathrm{~s})}{\partial \mathrm{s}^{2}}=-\mathrm{F}_{\mathrm{j}}^{\mathrm{b}} \cdot \mathrm{w}^{*}(\mathrm{~L})-\mathrm{F}_{\mathrm{i}}^{\mathrm{b}} \cdot \mathrm{w}^{*}(0)-\left.\mathrm{M}_{\mathrm{j}}^{\mathrm{b}} \cdot \frac{\partial \mathrm{w}^{*}}{\partial \mathrm{s}}\right|_{\mathrm{L}}+\left.\mathrm{M}_{\mathrm{i}}^{\mathrm{b}} \cdot \frac{\partial \mathrm{w}^{*}}{\partial \mathrm{s}}\right|_{0}
$$

Then, taking into account the properties of Dirac function and their inclusion in equations (31), (32) and (25), it was obtained:

$$
\int_{0}^{L} P_{0} \cdot \delta(x-v t) \cdot w^{*}(x) \cdot d x=p_{0} \cdot w^{*}(v t)
$$

The coefficients of Hermite polynomial are described by:

The expression in which no initial condition in the approach to the function $w(x)$ describing the beam deflection is taken into account results in the impossibility of solving the differential equation. For this reason, in the finite element method solving process, we will consider the process of two displacements and two other rotations. We assume that the $w(x, t)$ function can be accurately reproduced as a linear combination of polynomials of maximum third degree called Hermite polynomials indicated below.

$$
w(x, t)=\sum_{n=1}^{4} y_{n}(t) \cdot h_{n}(x)
$$

$$
\begin{gathered}
{\left[U_{i}\right] \rightarrow h_{1}(x)=1-3 \cdot\left(\frac{x}{L}\right)^{2}+2 \cdot\left(\frac{x}{L}\right)^{3}} \\
{\left[\theta_{i}\right] \rightarrow h_{2}(x)=L \cdot\left[\frac{x}{L}-2 \cdot\left(\frac{x}{L}\right)^{2}+\left(\frac{x}{L}\right)^{3}\right]} \\
{\left[U_{j}\right] \rightarrow h_{3}(x)=3 \cdot\left(\frac{x}{L}\right)^{2}-2 \cdot\left(\frac{x}{L}\right)^{3}} \\
{\left[\theta_{j}\right] \rightarrow h_{4}(x)=L \cdot\left(-\frac{x}{L}\right)^{2}+\left(\frac{x}{L}\right)^{3}}
\end{gathered}
$$

If the above dependencies are inserted into equation 34, it is obtained:

$$
w(x, t)=y_{i} \cdot h_{1}(x)+\theta_{i} \cdot h_{2}(x)+y_{j} \cdot h_{3}(x)+\theta_{j} \cdot h_{4}(x)
$$

So we can get speed and acceleration:

$$
\begin{gathered}
(\dot{x}, t)=\dot{y}_{i} \cdot h_{1}(x)+\dot{\theta}_{i} \cdot h_{2}(x)+\dot{y}_{i} \cdot h_{3}(x)+\dot{\theta}_{j} \cdot h_{4}(x) \\
w(\dot{x}, t)=\sum_{n=1}^{4} \dot{y}_{n}(t) \cdot h_{n}(x) \\
w(\ddot{x}, t)=\ddot{y}_{i} \cdot h_{1}(x)+\ddot{\theta}_{i} \cdot h_{2}(x)+\ddot{y}_{i} \cdot h_{3}(x)+\ddot{\theta}_{j} \cdot h_{4}(x) \\
w(\ddot{x}, t)=\sum_{n=1}^{4} \ddot{y}_{n}(t) \cdot h_{n}(x)
\end{gathered}
$$

If we also accept $w(x)$ as a function, it takes the properties of the Hermite function:

$$
\begin{gathered}
\int_{0}^{L} \rho(x) \cdot \sum_{n=1}^{4}\left[y_{n}(t) \cdot h_{n}(x)\right] \cdot h_{m}(x) d x+\int_{0}^{L} \sum_{n=1}^{4}\left[y_{n}(t) \cdot \frac{\partial^{2} h_{n}(x)}{\partial x^{2}}\right] E I(x) h_{m}(x) \partial x^{2} \\
=+F_{j}^{b} \cdot h_{m}(L)+F_{i}^{b} \cdot h_{m}(0)+\left.M_{j}^{b} \cdot \frac{\partial h_{m}(x)}{\partial x}\right|_{L}+\left.M_{i}^{b} \cdot \frac{\partial h_{m}(x)}{\partial x}\right|_{0}-P_{0} \cdot h_{m}(v t)
\end{gathered}
$$

This means that we will be able to describe mathematically the dynamics of the beam described by arrays:

$$
\left[\begin{array}{llll}
m_{11} & m_{12} & m_{13} & m_{14} \\
m_{21} & m_{22} & m_{23} & m_{24} \\
m_{31} & m_{32} & m_{33} & m_{34} \\
m_{41} & m_{42} & m_{43} & m_{44}
\end{array}\right]\left[\begin{array}{c}
\ddot{y}_{i}(v t) \\
\ddot{\theta}_{i}(v t) \\
\ddot{y}_{j}(v t) \\
\ddot{\theta}_{j}(v t)
\end{array}\right]+\left[\begin{array}{llll}
k_{11} & k_{12} & k_{13} & k_{14} \\
k_{21} & k_{22} & k_{23} & k_{24} \\
k_{31} & k_{32} & k_{33} & k_{34} \\
k_{41} & k_{42} & k_{43} & k_{44}
\end{array}\right]\left[\begin{array}{l}
y_{i}(v t) \\
\theta_{i}(v t) \\
y_{j}(v t) \\
\theta_{j}(v t)
\end{array}\right]=\left[\begin{array}{c}
F_{i}^{b}(v t) \\
M_{i}^{b}(v t) \\
F_{j}^{b}(v t) \\
M_{j}^{b}(v t)
\end{array}\right]-P_{0}\left[\begin{array}{l}
h_{1}(v t) \\
h_{2}(v t) \\
h_{3}(v t) \\
h_{4}(v t)
\end{array}\right]
$$

Where:

$$
\begin{aligned}
& M_{i j}=\int_{0}^{L} \rho(x) \cdot h_{i}(x) \cdot h_{j}(x) d x \\
& K_{i j}=\int_{0}^{L} h_{i}^{\prime \prime}(x) \cdot E I(x) \cdot h_{j}^{\prime \prime}(x) d x
\end{aligned}
$$

The resulting matrices are symmetric. If we combine them into pairs of so-called elementary matrices it is possible to obtain a global equation defining the dynamics of the beam formulated for the whole structure:

$$
M \ddot{y}+K y=-P_{0} h(v t)
$$

\section{Simulation RESULtS}

The simulation will be performed for a constant vertical force $\mathrm{P}=12 \mathrm{kN}$. As a design example, a variable cross section 
beam (as a turnout switch point) with supports between sleepers $\mathrm{L}=0.6 \mathrm{~m}$ will be used. For the calculations, the unit mass of the beam for the S62 rail and the flexural stiffnes $\mathrm{El}=1.96 \mathrm{GNm}^{2}$ were used. The system is loaded with a constant concentrated force $P_{0}=12 \mathrm{kN}$ moving at a constant speed $v=37 \mathrm{~m} / \mathrm{s}$. In the calculations, beam deflections and vibrations were analyzed depending on the position of the force moving along the beam. The results of the calculations are shown in Figure $4 \div$ Figure 6

Figure 4 shows the results of simulation tests of changes in deformation of the blade with a vertical force acting on the blade in case of excitation in the wave beam w $(z, t)$ such that conditions $z 1\left(L_{0}\right)=0.001 \mathrm{~m}, z 1\left(P_{0}\right)=-0.002 \mathrm{~m}$ are fulfilled at the moment. It follows that, when subjected to vertical and lateral forces (due to wheel/rail contact), the initial amplitude of vibration at the beginning of the beam is $3 \mathrm{~mm}$.

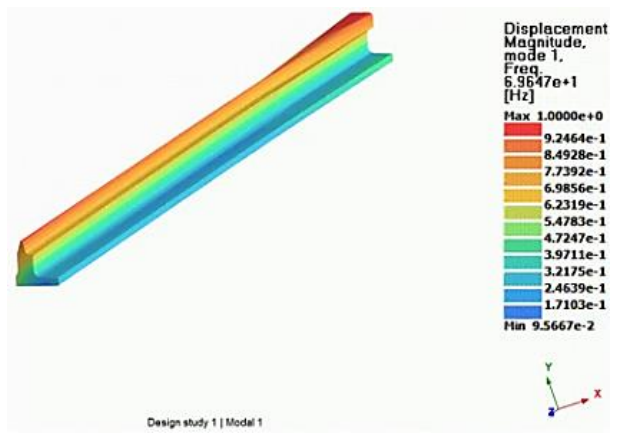

Fig. 4. First eigenmode for a variable cross section beam (switch point) for occurring displacements

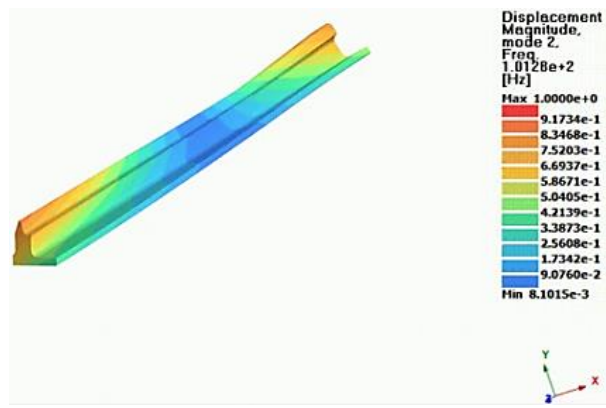

Fig. 5. Second eigenmode for a variable cross section beam (switch point) for occurring displacements

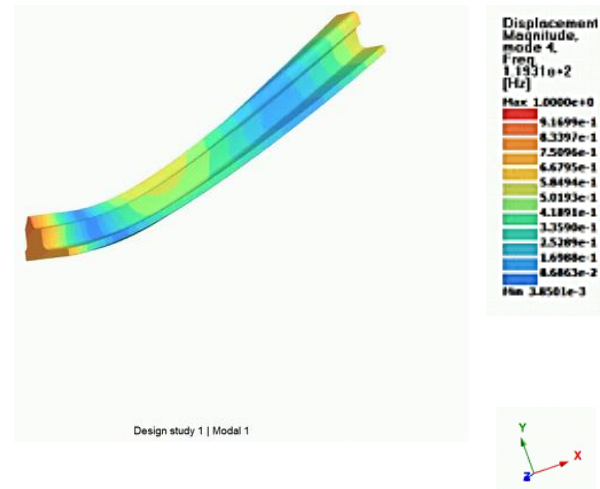

Fig. 6. Third eigenmode for a variable cross section beam (switch point) for the displacements occurring (two forces: vertical and transverse force resulting from wheel/rail contact) 


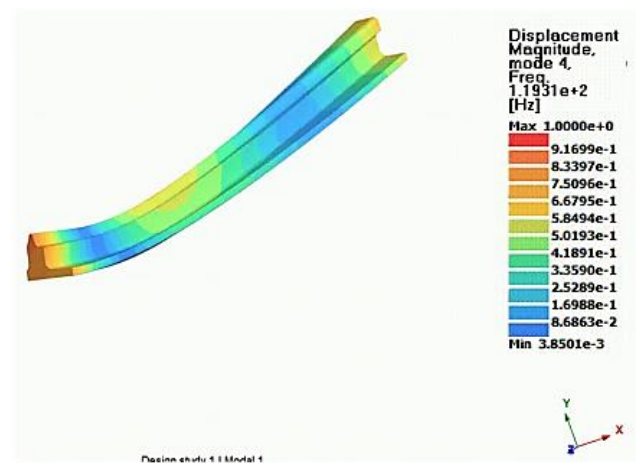

Fig. 7. Fourth eigenmode for a variable cross section beam (switch point) for occurring displacements (only vertical force acts)

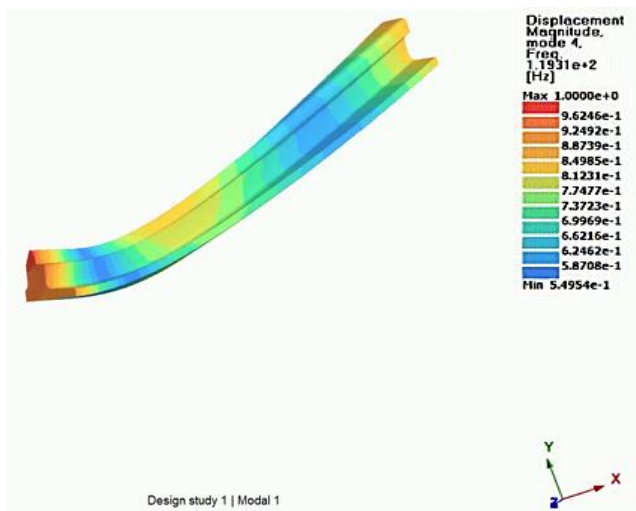

Fig. 8. Fourth upright form for a variable cross section beam (turnout blade) for occurring displacements (vertical and lateral force resulting from wheel/rail contact)

Analysis of the results of the simulation (Fig. $4 \div$ Fig. 8) shows that the eigenmodes of the switch point have lowfrequency components at the action of the normal force only, whereas in the case of the action of the normal and transverse force resulting from the wheel's contact with the switch point, the damping occurring in the switch point is very effective. In the form of solutions presented in equations (7) and (8) it was assumed that they represent the composition of individual wave modes. The solution of the whole problem of cooperation of the model of moving load on the blade is connected with the number of modes necessary to take into account in the adopted form of solutions the equations describing the load movement on the beam to ensure appropriate, assumed numerical convergence when determining the wave development coefficients. Numerical simulations of the displacement of vibrations of beams with variable cross-sections require calculations to be carried out at different values of given parameters (mass-inertia parameters and switch poin support parameters). The result of an exemplary simulation of beam vibrations described by the mathematical model in equation (7) and (8) for the vertical and transverse force resulting from the wheel/switch point contact is shown in Figure 8 . It is visible that the critical value of the amplitude of vibration displacements - critical in relation to the assumed value of deflections $z 1\left(L_{0}\right)=z 1\left(P_{0}\right)=5 \mathrm{~mm}$ - is exceeded

A simulation was also carried out to determine the maximum and minimum stresses in the switch point as beams of variable cross-section (Fig. 9 and Fig. 10).

Simulations have been performed to determine the displacement in the direction of the $\mathrm{XYZ}$ axis. These results are shown in Figure $11 \div$ Figure 13 .

Using the ANSYS program, a simulation was performed using the Van Mises method, which determined the maximum and minimum stresses along the needle. The structure of the switch point is similar to the system with variable stiffness, which is often considered in cutting systems [23]. The results are shown in Figure 14

The simulations carried out allowed to determine the deformations in three directions caused by the load. The stress distribution was also obtained, which indicates the influence of the load on the formation of deformations and displacements in the analyzed case. The maximum beam deflection, i.e. the elastic displacement in the $z$-axis direction, occurs between the sleepers and is $1.1398 \mathrm{~mm}$, whereas the maximum longitudinal displacement of the beam of $3.2194 \mathrm{~mm}$ occurs at its end. 


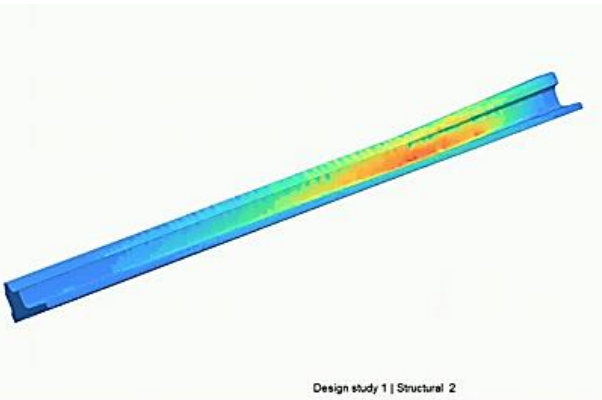

Major
Principal
Stress [MPa]

$\operatorname{Max} 1.0346 \mathrm{e}-1$
B.1919e-2

8.1919e-2

$6.6841 \mathrm{e}-2$
$-5.9302 \mathrm{e}-2$

$-5.1764 e^{-2}-2$

$4.4225 e-2$
$3.6686-2$
$2.9148 \mathrm{e}-2$

$2.1609 \mathrm{e}-2$
$-1.400 \mathrm{e}-2$
$-65313 \mathrm{e}-3$

tin $-4.2383 \mathrm{e}-3$

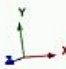

Fig. 9. Maximum switch point stress - variable cross section beams

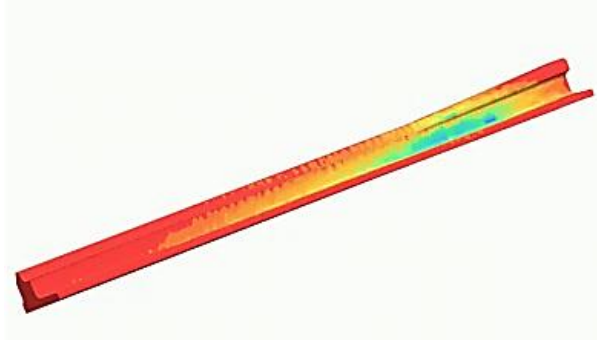

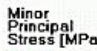

$\max 3.4095 e^{-4}$

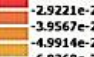

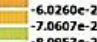

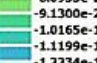

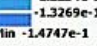

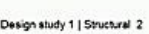

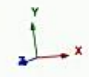

Fig. 10. Minimum switch point stress - variable cross section beams

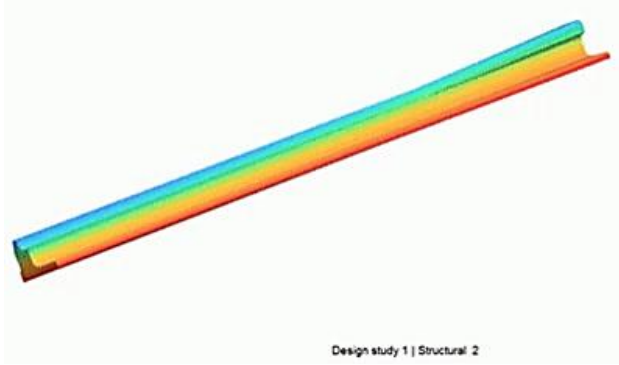

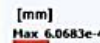

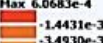

$=2.752928$

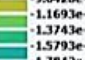

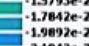

Ninn 2.390220 .2

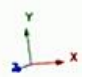

Fig. 11. Movement of the switch point in the $x$-direction of the variable cross section beam

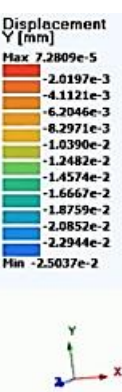

Desionstory 11 senctual 2

Fig. 12. Movement of switch point in the direction of $y$ - variable cross section beams 

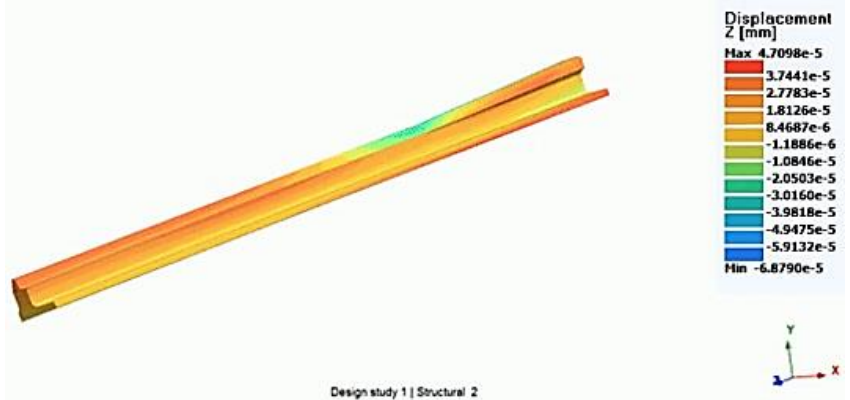

Fig. 13. Movement of the switch point in the z-direction of a variable cross section beam
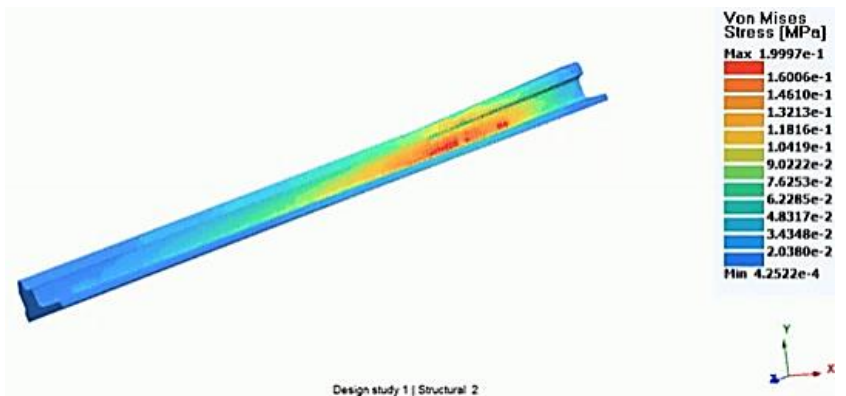

Fig. 14. Simulation of Von Mises for the blade - variable cross section beams

\section{CONCLUSIONS}

Analysis of the results of simulations carried out on the adopted model of displacement of vibrations of the beam model is dominated by low-frequency components, similarly as in the case of a beam with vertical force occurring between the wheel and the switch point. For a model with vertical force and transverse force resulting from wheel-rail contact phenomena, there is greater damping of eigenmodes than for a model of vertical force movement in wheel-rail contact. The analysis of the results of simulation of beam vibration displacements resulting from the cooperation of the wheel and the switch point shows that the load movement in the form of force is accompanied by a wave string (three running and three standing wave modes were analyzed), in which the assembly can be seen the maximum preceding and the minimum "backward" displacements, while the ratio of the absolute maximum to the absolute minimum "backward" wave is more than $9 \mathrm{~mm}$

During the simulation of higher load motion velocities and analysis of subsequent excited natural frequencies of the point switch own vibrations, a spatial-time diagram of vibration displacements shows a clearer force interaction with the vertical and transverse force resulting from the wheel's contact with the switch point, two extrema running parallel to each other - maximum waves (situated at an angle to the time axis - in the $w(z, t)$ system) become visible.

The numerical analysis carried out in this paper made it possible to determine the displacements and deformations in the models subjected to moving loads. The presented results of numerical analysis were obtained in the ANSYS 17 Workbench module. Continuous beam solutions using analysis methods are highly complex and time-consuming while ANSYS allows quick numerical calculations using FEM.

\section{WSPÓŁPRACA POJAZDU SZYNOWEGO Z ROZJAZDEM}

Artykuł przedstawia model matematyczny iglicy rozjazdu kolejowego o promieniu $r \geq 1200 \mathrm{~m}$. Iglica traktowana jest jako belka o zmienne sztywnościizmiennymmomenciebezwladności(wzdłużchugości iglicy). Przedstawiono symulagię modelu matematycznego iglicy obciążoną stała sitą w kontakcie koła z szyną, korzystając z rzeczywistych parametrówtakiejiglicy.

Slowakluczowe: rozjazd, pojazd szynowy, postaciwłasne, krzywizna

\section{BIBLIOGRAPHY}

[1] Kassa E., Andersson C., Nielsen Jens C. O. (2006) Simulation of dynamic interaction between train and railway turnout. Vehicle System Dynamics, Vol. 44, No. 3, March 2006, pp. 247-258

[2] Wan C., Markine V.L., Shevtsov I.Y., Dollevoet R.P.B.J. (2013) Improvement of train-track interaction in turnouts by optimising the shape of crossing nose. IAVSD 2013: 23 ${ }^{\text {rd }}$ International Symposium on Dynamics of Vehicles on Roads and Tracks, Qingdao, China, 19-23 August 2013

[3] Lu C., Rodríguez-Arana B., Prada J.G., Meléndez J., MartínezEsnaola J.M. (2019) A Full explicit finite element simulation for the study of interaction between wheelset and switch panel. Vehicle System Dynamics, International Journal of Vehicle Mechanics and Mobility, DOI: 10.1080/00423114.2019.1575425 
[4] Pålsson Björn A. (2015) Optimisation of railway crossing geometry considering a representative set of wheel profiles. Vehicle System Dynamics, Vol. 53, No. 2, 274-301, DOI: 10.1080/00423114.2014.998242

[5] Pålsson Björn A., Nielsen Jens C.O. (2012) Wheel-rail interaction and damage in switches and crossings. Vehicle System Dynamics, Vol. 50, No. 1, January 2012, pp. 43-58

[6] Pålsson Björn A., Nielsen, Jens C.O. (2015) Dynamic vehicle-track interaction in switches and crossings and the influence of rail pad stiffness - field measurements and validation of a simulation model. Vehicle System Dynamics, 2015, Vol. 53, No. 6, 734-755, DOI: 10.1080/00423114.2015.1012213

[7] Pålsson Björn A. (2013) Design optimisation of switch rails in railway turnouts. Vehicle System Dynamics, DO 10.1080/00423114.2013.807933

[8] Pålsson Björn A. (2014) Optimisation of Railway Switches and Crossings. Thesis For The Degree Of Doctor Of Philosophy In Solid And Structural Mechanics, Department of Applied Mechanics, Chalmers University Of Technology, Göteborg Sweden

[9] Nicklisch D., Kassa E., Nielsen J., Ekh,M., Iwnicki S. (2010) Geometry and stiffness optimization for switches and crossings, and simulation of material degradation. Proceedings of the Institution of Mechanical Engineers, Part F: Journal of Rail and Rapid Transit, Volume: 224, Issue: 4, pp. 279-292. DOI: 10.1243/09544097JRRT348

[10] Kassa E., Nielsen C.O. (2008) Stochastic analysis of dynamic interaction between train and railway turnout. Vehicle System Dynamics, Vol. 46, No. 5, May 2008, pp. 429-449

[11] Wan Ch., Markine V., Shevtsov I. (2014) Optimisation of the elastic track properties of turnout crossings. Proceedings of the Institution of Mechanical Engineers, Part F: Journal of Rail and Rapid Transit, Volume: 230, Issue: 2, pp. 360-373, DOI: $10.1177 / 0954409714542478$

[12] Zhu J.Y Thompson DJ. (2009) Characterization of forces, dynamic response, and sound radiation from an articulated switch sleeper in a turnout system. Proceedings of the Institution of Mechanical Engineers, Part F: Journal of Rail and Rapid Transit, DOl: 10.1243/09544097JRRT302 Volume: 224, Issue: 2 pp. 53-60

[13] Kassa $E$, Johansson $G$. (2006) Simulation of train-turnout interaction and plastic deformation of rail profiles. Vehicle System Dynamics, Vol. 44, Supplement, pp. 349-359
[14] Ekberg A., Paulsson B. (2010) Innotrack, Concluding Technica Report. International Union of Railways (UIC), Printing: Intellecta Infolog, Solna, ISBN: 978-2-7461-1850-8

[15] Chiou S-B., Yen J.-Y. (2017) Modeling of railway turnout geometry in the frog area with the vehicle wheel trajectory. Proceedings of the Institution of Mechanical Engineers, Part $F$ : Journal of Rail and Rapid Transit, Volume: 232, Issue: 6 , pp. 1598-1614, DOI: 10.1177/0954409717739734

[16] Wan C., Markine V.L., Shevtsov I.Y. (2014) Improvement of vehicle-turnout interaction by optimising the shape of crossing nose. Vehicle System Dynamics, Vol. 52, No. 11, pp. 1517-1540, DOI: 10.1080/00423114.2014.944870

[17] Kassa E., Nielsen J. C.O. (2008) Dynamic interaction between train and railway turnout: full-scale field test and validation of simulation models. Vehicle System Dynamics, International Journal of Vehicle Mechanics and Mobility, Vol. 46, Supplement pp. 521-534, DOI: 10.1080/00423110801993144

[18] Alfi S., Bruni S. (2009) Mathematical modelling of train-turnout interaction. Vehicle System Dynamics, International Journal of Vehicle Mechanics and Mobility, Vol. 47, No. 5, pp. 551-574, DOI: 10.1080/00423110802245015

[19] Xin L, Markine V.L., Shevtsov I.Y. (2016) Numerical analysis of the dynamic interaction between wheel set and turnout crossing using the explicit finite element method. Vehicle System Dynamics, International Journal of Vehicle Mechanics and Mobility, DOI: 10.1080/00423114.2015.1136424

[20] Kisilowski J., Kowalik R., Kwiecień K. (2014) Analiza dynamiczna przejazdu pociągów szybkiej kolei przez rozjazd kolejowy. Logistyka 6/2014, pp. 5465-5477

[21] Kwiecień K. (2017) Wybrane zagadnienia dynamiki iglicy rozjazdu kolejowego dla kolei dużych prędkości. Rozprawa doktorska, UTH Radom

[22] Kisilowski J., Skopińska H. (1983) Dynamika krzyżownicy rozjazdu zwyczajnego, Archiwum Inżynierii Lądowej, Tom XXIX, 4/83, Warszawa

[23] Szparaga Ł., Ratajski J., Olik R. (2010) Modelowanie i symulacja numeryczna stanu naprężeń i odkształceń w warstwie wierzchniej noża strugarki do obróbki drewna pokrytego powłoką przeciwzużyciową. Inżynieria Materiałowa 4/2010, pp. $1249-1254$ 